\title{
Alterations of Peripheral Blood T Cell Subsets following Donor Lymphocyte Infusion in Patients after Allogeneic Stem Cell Transplantation
}

\author{
Ann-Kristin Schmaelter ${ }^{1, *(\mathbb{D}}$, Johanna Waidhauser ${ }^{1} \mathbb{D}$, Dina Kaiser ${ }^{2}$, Tatjana Lenskaja ${ }^{3}$, Stefanie Gruetzner ${ }^{3}$, \\ Rainer Claus ${ }^{1}$ (D), Martin Trepel ${ }^{1}$, Christoph Schmid ${ }^{1,+}$ and Andreas Rank ${ }^{1, \dagger}$ \\ 1 Department of Hematology and Oncology, University Hospital Augsburg, 86156 Augsburg, Germany; \\ Johanna.Waidhauser@uk-augsburg.de (J.W.); Rainer.Claus@uk-augsburg.de (R.C.); \\ Martin.Trepel@uk-augsburg.de (M.T.); Christoph.Schmid@ik-augsburg.de (C.S.); \\ Andreas.Rank@uk-augsburg.de (A.R.) \\ 2 Medical Faculty, Ludwig Maximilian University of Munich,80539 Munich, Germany; dhmak@gmx.de \\ 3 Institute of Transfusion Medicine and Hemostasis, University Hospital Augsburg, 86156 Augsburg, Germany; \\ Tatjana.Lenskaja@uk-augsburg.de (T.L.); Stefanie.Gruetzner@uk-augsburg.de (S.G.) \\ * Correspondence: Ann-Kristin.Schmaelter@uk-augsburg.de \\ + These authors contributed equally to this work and share last authorship.
}

Citation: Schmaelter, A.-K.; Waidhauser, J.; Kaiser, D.; Lenskaja, T.; Gruetzner, S.; Claus, R.; Trepel, M.; Schmid, C.; Rank, A. Alterations of Peripheral Blood T Cell Subsets following Donor Lymphocyte Infusion in Patients after Allogeneic Stem Cell Transplantation. Hemato 2021, 2, 692-702. https://doi.org/ 10.3390/hemato2040046

Received: 10 October 2021

Accepted: 17 November 2021

Published: 22 November 2021

Publisher's Note: MDPI stays neutra with regard to jurisdictional claims in published maps and institutional affiliations.

Copyright: (c) 2021 by the authors. Licensee MDPI, Basel, Switzerland. This article is an open access article distributed under the terms and conditions of the Creative Commons Attribution (CC BY) license (https:/ creativecommons.org/licenses/by/ $4.0 /)$.
Abstract: Donor lymphocyte infusion (DLI) after allogeneic stem cell transplantation (alloSCT) is an established method to enhance the Graft-versus-Leukemia (GvL) effect. However, alterations of cellular subsets in the peripheral blood of DLI recipients have not been studied. We investigated the changes in lymphocyte subpopulations in 16 patients receiving DLI after successful alloSCT. Up to three DLIs were applied in escalating doses, prophylactically for relapse prevention in high-risk disease $(n=5)$, preemptively for mixed chimerism and/or a molecular relapse/persistence $(n=8)$, or as part of treatment for hematological relapse $(n=3)$. We used immunophenotyping to measure the absolute numbers of $\mathrm{CD} 4+, \mathrm{CD} 8+, \mathrm{NK}$, and CD56+ T cells and their respective subsets in patients peripheral blood one day before DLI $(\mathrm{d}-1)$ and compared the results at day +1 and +7 post DLI to the values before DLI. After the administration of $1 \times 10^{6} \mathrm{CD} 3+$ cells $/ \mathrm{kg}$ body weight, we observed an overall increase in the CD8+ and CD56+ T cell counts. We determined significant changes between day -1 compared to day +1 and day +7 in memory and activated CD8+ subsets and CD56+ T cells Applying a higher dose of DLI $\left(5 \times 10^{6} \mathrm{CD} 3+\right.$ cells $\left./ \mathrm{kg}\right)$ led to a significant increase in the overall counts and subsets of CD8+, CD4+, and NK cells. In conclusion, serial immune phenotyping in the peripheral blood of DLI recipients revealed significant changes in immune effector cells, in particular for various CD8+ T cell subtypes, indicating proliferation and differentiation.

Keywords: donor lymphocyte infusion; T lymphocytes; allogeneic stem cell transplantation; graftversus-leukemia effect; graft-versus-host disease; immunophenotyping

\section{Introduction}

Donor lymphocyte infusion (DLI) after allogeneic stem cell transplantation (alloSCT) is a form of adaptive immunotherapy. In 1990, it was first demonstrated in patients with relapse of chronic myeloid leukemia (CML) that DLI can augment the allogeneic Graftversus-Leukemia (GvL) effect [1]. Later, DLI was shown to be effective in other diseases and clinical situations [2-4]. There are three major indications for the application of DLI: Prophylactic DLI can be applied to prevent relapse in patients with a high-risk disease, due to, e.g., high-risk cytogenetic or molecular genetic changes associated with a poor prognosis [5,6] or in patients who were transplanted in advanced stages [7].

Preemptive DLI can be performed in patients with a cytogenetic or molecular genetic relapse or patients showing minimal residual disease (MRD) [8] or an incomplete mixed 
chimerism (MC) [9-11] following alloSCT. Finally, therapeutic DLI, given alone or in combination with chemotherapy and other anti-leukemic drugs, is a frequently used strategy in hematological or extramedullary relapse post-transplant [3,7]. Major complications of DLI are pancytopenia, as well as acute and chronic Graft-versus-Host disease (GvHD) [12].

Both functional changes of transfused lymphocytes and the mechanisms of the GvL reaction induced by DLI are not well understood. It is known that CD3+ T cells trigger the GvL reaction by recognizing recipient alloantigens on leukemic cells [13]. They mainly target minor histocompatibility antigens, which may differ even in human leukocyte antigen (HLA) identic donors and recipients [14], or tumor/leukemia associated antigens [15]. Thus far, it is unclear to what extent different $\mathrm{CD} 3+$ lymphocyte subsets are responsible as effector cells for GvL effects applied by DLI, or which pathways are triggered by DLI $[12,16]$. In the present study, flow cytometry was used to evaluate qualitative and quantitative changes in B and T lymphocyte subsets in the peripheral blood following DLI applied in escalating doses.

\section{Materials and Methods}

\subsection{Patients}

We included 16 consecutive patients who received prophylactic $(n=5)$, preemptive ( $n=8)$, or therapeutic $(n=3)$ DLI at Augsburg University Hospital between 2016 and 2018, according to the institutional guidelines. The study was approved by the institutional ethical review board; patients provided written informed consent. As described [17,18], the prerequisites for DLI were an established donor chimerism, cessation of immunosuppressive medication at least four weeks before the first DLI, and the absence of any signs of infection or GvHD.

\subsection{Donor Lymphocyte Infusions}

All donor lymphocytes were collected after transplantation from the original stem cell donor. The first DLI in each patient was applied freshly, the following were cryopreserved according to institutional guidelines. The initial cell doses were based on the donor type, clinical situation, and individual history of prior GvHD: A starting dose of $2 \times 10^{5} \mathrm{CD} 3+$ cells $/ \mathrm{kg}$ patient bodyweight was applied to recipients receiving DLI preemptively or prophylactically from unrelated or haploidentical transplants.

In contrast, DLI after matched sibling donor transplants or given in therapeutic indication was applied with a higher initial dose of $1 \times 10^{6}$ to $5 \times 10^{6} \mathrm{CD} 3+$ cells $/ \mathrm{kg}$. A dose escalation between 0.5 and $1 \log$ was carried out every four weeks in the absence of GvHD or progression of the underlying malignancy. We investigated lymphocyte subsets before and after the application of $2 \times 10^{5}\left(n=10\right.$ patients), $1 \times 10^{6}(n=13$ patients), and $5 \times 10^{6}$ ( $n=15$ patients) CD3+ lymphocytes $/ \mathrm{kg}$. Blood samples from 32 healthy blood donors or volunteers, matched by age and sex, were analyzed as controls.

\subsection{Analysis of Lymphocytes and Subsets by Immunophenotyping}

EDTA peripheral blood was collected before $(\mathrm{d}-1)$, at day +1 and day +7 after DLI. All blood samples were processed within $24 \mathrm{~h}$. Blood samples were distributed into seven $50 \mu \mathrm{L}$ aliquots, and antibodies were added followed by $15 \mathrm{~min}$ incubation. Erythrocyte lysis was conducted by addition of $500 \mu \mathrm{L}$ Versal Lyse for $15 \mathrm{~min}$. Subsequently, the samples were washed with PBS. Flow cytometry was used to identify and analyze frequencies of B and T lymphocytes and their respective subsets.

After cell staining with commercial fluoreszeinisothiocyanat (FITC-), phycoerythrin (PE-), phycoerythrin Texas red-X (ECD-), and phycoerythrin-cyanin (PC5- and PC7-) labeled antibodies purchased from Beckman Coulter (Brea, CA, USA) and Biolegend (San Diego, CA, USA), samples were analyzed by flow cytometry using FC500 from Beckman Coulter (Supplemental Table S1). For all lymphocyte subsets, percentages were determined, and the absolute numbers were calculated. The absolute leukocyte counts were measured with Stem-Count (Stem-Kit, Beckman Coulter) using CD45-FITC. A minimum of 10,000 events 
per aliquot of each sample was analyzed. Lymphocytes were identified by using forward scatter and side scatter. To divide lymphocytes into different subsets, established standard and well-described gating strategies were used [19-21] (Supplemental Figure S1 and Table S2).

\subsection{Definitions}

Definitions of complete hematological, molecular response (CR and CRm), relapse, and acute and chronic GvHD were defined as described [22]. The overall survival (OS) was calculated between the date of first DLI and date of death or last follow-up. A clinical response to DLI was defined by achievement of hematological CR or partial response after therapeutic DLI and by the achievement of CRm or complete donor chimerism after preemptive DLI. Whole and T cell chimerism was measured before and after completion of DLI. Mixed chimerism was defined by the detection of any recipient marker in our PCR based chimerism measurement. Following prophylactical DLI, a response obviously could not be defined.

\subsection{Statistics}

The study was prospective and designed as a hypothesis-generating analysis. The results of cellular analysis are given as the median values of all measured numbers for descriptive analysis. To adjust to the relatively low patient numbers and the serial measurement, we used the Wilcoxon signed-rank test for associated samples. We compared the results at day +1 and day +7 post DLI each to the measurement before DLI. As a control, lymphocyte counts of 32 healthy controls were compared to the numbers for patients before the application of the first DLI. $p$-values $<0.05$ were regarded as statistically significant. Statistical analyses were performed with SPSS 24.0 (SPSS Inc., Chicago, IL, USA).

\section{Results}

\subsection{Patient Characteristics and Clinical Outcomes}

Sixteen patients with various hematologic malignancies were included in this study. At time of DLI, some patients had suffered from thrombopenia and/or anemia; however, no patient was transfusion dependent. The overall $\mathrm{T}$ cell chimerism was $>97 \%$ in all informative patients. The reason for DLI was hematological relapse (therapeutic DLI, $n=3$ ), MC or molecular relapse (preemptive DLI, $n=8$ ), or maintenance for relapse prevention in high-risk disease (prophylactic DLI, $n=5$ ). The median time from alloSCT to first DLI was 8 months (range 5 to 44). The patient characteristics are shown in Tables 1 and S3.

The median follow-up from first DLI was 28.6 months (range 7 to 47 ). Clinical results from individual patients are summarized in Supplemental Table S3. In brief, at last followup, two out of five of the recipients of prophylactical DLI were still in remission after DLI, whereas three had relapsed. None of the patients receiving therapeutic DLI had become long-term survivors. In contrast, the results were more encouraging after preemptive DLI, since the response could be clearly documented either by conversion of mixed to full chimerism or by the achievement of complete molecular remission in all eight patients. The median time from first DLI to best response was 6.4 months (range 3-12 months). The OS from first DLI at 1 and 2 years for the entire cohort were $75 \%$ and $61 \%$, respectively (Supplemental Figure S2A). Considering only patients who had received prophylactic or preemptive DLI, the two-year OS was 75\% (Supplemental Figure S2B). 
Table 1. Patient characteristics.

\begin{tabular}{|c|c|c|c|}
\hline Variables & & & Results \\
\hline Age; med & & & $55.5 / 56.9(41-70)$ \\
\hline \multicolumn{4}{|l|}{ Gender } \\
\hline & male; $n(\%)$ & & $11(68.75)$ \\
\hline & female; $n(\%)$ & & $5(31.25)$ \\
\hline \multicolumn{4}{|l|}{ Donor } \\
\hline & URD; $n(\%)$ & & $10(62.5)$ \\
\hline & $\mathrm{MSD} ; n(\%)$ & & $3(18.8)$ \\
\hline & Haplo; $n(\%)$ & & $3(18.8)$ \\
\hline \multicolumn{4}{|c|}{ Indication for alloSCT } \\
\hline & AML; $n(\%)$ & & $10(62.5)$ \\
\hline & & de novo AML; $n$ ( $\%$ of AML) & $3(30)$ \\
\hline & & sAML; $n(\%$ of AML) & $6(60)$ \\
\hline & & tAML; $n$ (\% of AML) & $1(10)$ \\
\hline & CML; $n(\%)$ & & $2(12.5)$ \\
\hline & Multiple Myeloma; $n(\%)$ & & $3(18.75)$ \\
\hline & Pro-B-ALL; $n(\%)$ & & $1(6.25)$ \\
\hline \multicolumn{4}{|c|}{ Indication for DLI } \\
\hline & Prophylactic *; $n(\%)$ & & $5(31.3)$ \\
\hline & Therapeutic ${ }^{* *} ; n(\%)$ & & $3(18.8)$ \\
\hline & Preemptive *; $n(\%)$ & & $8(50)$ \\
\hline & & Mixed chimerism; $n$ & 6 \\
\hline & & Molecular relapse; $n$ & 1 \\
\hline & & $\begin{array}{l}\text { Mixed chimerism and } \\
\text { molecular relapse; } n\end{array}$ & 1 \\
\hline \multicolumn{4}{|c|}{ Initial DLI dose } \\
\hline & $2 \times 10^{5} \mathrm{CD} 3+$ lymphocytes $/ \mathrm{kg}$ & & $10(62.5)$ \\
\hline & $1 \times 10^{6} \mathrm{CD} 3+$ lymphocytes $/ \mathrm{kg}$ & & $5(31.3)$ \\
\hline & $5 \times 10^{6} \mathrm{CD} 3+$ lymphocytes $/ \mathrm{kg}$ & & $1 *(6)$ \\
\hline \multicolumn{3}{|c|}{ Time alloSCT to 1. DLI; median (range in months) } & $8(5-44)$ \\
\hline \multicolumn{3}{|c|}{ Time 1. DLI to 2. DLI; median (range in days) } & $28(21-215)$ \\
\hline \multicolumn{3}{|c|}{ Time 2. DLI to 3. DLI; median (range in days) } & $28(27-177)$ \\
\hline
\end{tabular}

* Prophylactic and preemptive DLI were given without additional anti-tumor medication. ${ }^{* *}$ Therapeutic DLI was given as part of multimodal regimen; for details see Table S3.

Four patients developed acute GvHD upon application of DLI reaching grade I $(n=2)$ and II and IV ( $n=1$ each). Two of these and one additional patient developed chronic GvHD (Supplemental Table S3).

\subsection{Analysis of Lymphocytes and Subsets}

\subsubsection{Baseline levels}

Baseline cellular status of our patients (obtained at day -1 before the first DLI) were first compared to a healthy control group $(n=32)$, matched by age and gender. The measurements revealed substantial differences regarding various lymphocyte subsets. In particular, the total lymphocyte counts and CD4+ subsets were significantly lower in patients compared to the healthy control group illustrating an insufficient T-cell recovery among transplant recipients (Supplemental Table S4).

\subsubsection{The Total Lymphocytes and CD3+ Lymphocytes}

We measured different lymphocyte subsets before and after the application of $2 \times 10^{5}$, $1 \times 10^{6}$, and $5 \times 10^{6} \mathrm{CD} 3+$ lymphocytes $/ \mathrm{kg}$. Applying DLI even in higher doses did not lead to a significant increase of total lymphocytes in the peripheral blood (median of $1117 / \mu \mathrm{L}$ before the first DLI compared to a median of $1315 / \mu \mathrm{L}$ at day +7 after the last DLI. Similarly, no significant changes were observed with respect to CD3+ cells (Figure 1). 

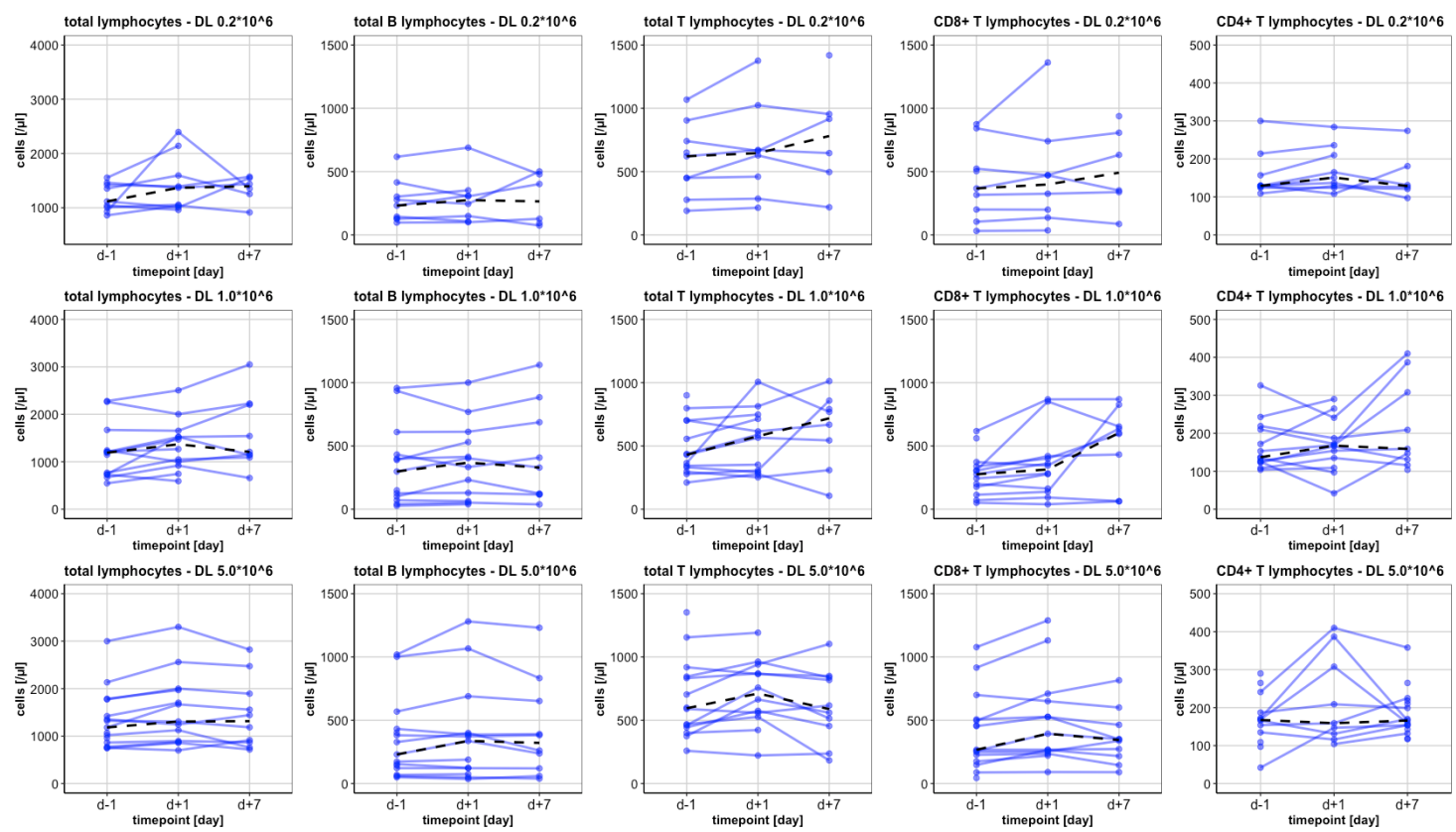

Figure 1. Graphic illustration of measurements of total lymphocytes (first column), B lymphocytes (second column) and $\mathrm{T}$ lymphocytes (third column), CD8+ (fourth column) and CD4+ lymphocytes (fifth column) at day (d) $-1, d+7$, and d + 7 after application of DLI in escalating doses of $2 \times 10^{5}$ (first row), $1 \times 10^{6}$ (second row), and $5 \times 10^{6}$ (third row) CD3+ lymphocytes / $\mathrm{kg}$ patient body weight.

\subsubsection{CD4+ Lymphocytes}

Regarding the total CD4+ lymphocytes, we observed an increase at day +1 only after the application of the highest dose of $5 \times 10^{6} \mathrm{CD} 3+$ cells $/ \mathrm{kg}(p=0.033$; Figure 1$)$. Among CD4+ subsets, memory $(p=0.028)$, central memory $(p=0.019)$, regulatory $(p=0.003)$, and CD25+ $(p=0.019)$ lymphocytes showed a significant increase. However, these changes were not observed anymore at day +7 (Table 2).

Table 2. CD4+ lymphocytes.

\begin{tabular}{|c|c|c|c|c|c|c|c|c|c|c|}
\hline \multirow[t]{2}{*}{ Dose } & \multicolumn{5}{|c|}{$1 \times 10^{6}$} & \multicolumn{5}{|c|}{$5 \times 10^{6}$} \\
\hline & $d-1$ & $d+1$ & $p(\mathrm{~d}-1 \mathrm{vs} . \mathrm{d}+1)$ & $d+7$ & $p(\mathrm{~d}-1$ vs. $\mathrm{d}+7)$ & $d-1$ & $d+1$ & $p(\mathrm{~d}-1$ vs. $\mathrm{d}+1)$ & $d+7$ & $p(\mathrm{~d}-1$ vs. $\mathrm{d}+7)$ \\
\hline $\begin{array}{c}\text { CD4+ } \\
\text { Lymphocytes }\end{array}$ & $137[104 ; 326]$ & $166[42 ; 290]$ & 0.929 & $159[104 ; 410]$ & 0.11 & $166[117 ; 358]$ & $219[119 ; 400]$ & $\underline{0.033}$ & $165[50 ; 383]$ & 0.721 \\
\hline memory & $125[101 ; 286]$ & $146[39 ; 254]$ & 0.929 & $156[85 ; 365]$ & 0.066 & $155[107 ; 318]$ & $197[155 ; 359]$ & $\underline{0.028}$ & $158[38 ; 340]$ & 0.859 \\
\hline central memory & $62[21 ; 618]$ & $69[18 ; 141]$ & 0.424 & $65[33 ; 225]$ & 0.093 & $69[30 ; 191]$ & $95[32 ; 232]$ & $\underline{0.019}$ & $83[19 ; 210]$ & 0.953 \\
\hline naive & $8[1 ; 45]$ & $8[1 ; 55]$ & 0.859 & $9[5 ; 47]$ & $\underline{0.011}$ & $10[1 ; 57]$ & $11[1 ; 46]$ & 0.182 & $9[2 ; 52]$ & 0.441 \\
\hline $\begin{array}{l}\text { effector } \\
\text { memory }\end{array}$ & $64[37 ; 151]$ & $77[21 ; 164]$ & 1 & $84[45 ; 249]$ & 0.214 & $80[44 ; 140]$ & $86[37 ; 138]$ & 0.286 & $71[22 ; 139]$ & 0.953 \\
\hline EMRA & $24[1 ; 90]$ & $22[2 ; 70]$ & 0.213 & $37[2 ; 108]$ & 0.441 & $31[3 ; 77]$ & $31[3 ; 69]$ & 0.093 & $26[1 ; 75]$ & 0.26 \\
\hline HLA-DR+ & $62[12 ; 90]$ & $56[9 ; 103]$ & 0.722 & $74[10 ; 149]$ & 0.327 & $68[12 ; 145]$ & $83[11 ; 150]$ & 0.117 & $66[2 ; 143]$ & 0.333 \\
\hline CD69+ & $11[3 ; 22]$ & $8[2 ; 20]$ & 0.424 & $9[4 ; 166]$ & 0.26 & $6[3 ; 20]$ & $9[3 ; 28]$ & 0.272 & $6[4 ; 19]$ & 0.959 \\
\hline Th1 & $14[1 ; 62]$ & $17[3 ; 39]$ & 0.286 & $19[6 ; 87]$ & 0.26 & $21[1 ; 55]$ & $30[2 ; 72]$ & 0.209 & $21[1 ; 54]$ & 0.594 \\
\hline Th2 & $13[2 ; 56]$ & $9[6 ; 42]$ & 0.213 & $21[2 ; 131]$ & 0.401 & $15[1 ; 53]$ & $15[1 ; 53]$ & 0.099 & $16[2 ; 42]$ & 0.646 \\
\hline Th17 & $12[0 ; 64]$ & $7[0 ; 57]$ & 0.333 & $7[2 ; 76]$ & 0.889 & $11[2 ; 74]$ & $13[2 ; 70]$ & 0.155 & $11[0 ; 78]$ & 0.878 \\
\hline regulatory & $2[1 ; 26]$ & $2[1 ; 22]$ & 1 & $2[1 ; 27]$ & 0.678 & $2[1 ; 19]$ & $3[1 ; 20]$ & $\underline{0.003}$ & $2[1 ; 5]$ & 0.721 \\
\hline CD25+ & $1[0 ; 13]$ & $1[0 ; 13]$ & 0.374 & $1[0 ; 10]$ & 0.594 & $1[0 ; 7]$ & $2[0 ; 8]$ & $\underline{0.019}$ & $1[1 ; 2]$ & 0.959 \\
\hline
\end{tabular}

Numbers are median values / $\mu \mathrm{L}$ and minimum and maximum values in square brackets. EMRA: effector memory RA+.

Statistically significant increases after the application of $2 \times 10^{5}$ and $1 \times 10^{6} \mathrm{CD} 3+$ cells $/ \mathrm{kg}$ involved only naïve, HLA-DR+, and Th2 CD4+ subsets; however, the overall cell counts were extremely low (Tabes 2 and S5). 


\subsubsection{CD8+ Lymphocytes}

Following the smallest dose of $2 \times 10^{5} \mathrm{CD} 3+$ cells $/ \mathrm{kg}$, we did not see any significant increase in the total CD8+ lymphocytes (Supplemental Table S6). In contrast, at day +1 and day +7 post DLI of $1 \times 10^{6} \mathrm{CD} 3+$ cells $/ \mathrm{kg}$, we observed significant differences in the overall number of CD8+ lymphocytes and various subsets (Figure 1, Table 3). The median number of total CD8 + cells increased moderately after DLI until day $+1(p=0.023)$ and showed a doubling at day $+7(p=0.011)$. The increase at day +1 could be observed within the CD8+ subsets of naïve $(p=0.041)$, EMRA $(p=0.041)$, intermediate $(p=0.015)$, exhausted $(p=0.034)$, and activated (HLA-DR $+; p=0.041)$ cytotoxic T lymphocytes.

Table 3. CD8+ lymphocytes and CD56+ T cells.

\begin{tabular}{|c|c|c|c|c|c|c|c|c|c|c|}
\hline \multirow[t]{2}{*}{ Dose } & \multicolumn{5}{|c|}{$1 \times 10^{6}$} & \multicolumn{5}{|c|}{$5 \times 10^{6}$} \\
\hline & $\mathrm{d}-1$ & $d+1$ & $p(\mathrm{~d}-1$ vs. $\mathrm{d}+1)$ & $d+7$ & $p(\mathrm{~d}-1$ vs. $\mathrm{d}+7)$ & $\mathrm{d}-1$ & $d+1$ & $p(\mathrm{~d}-1$ vs. $\mathrm{d}+1)$ & $d+7$ & $p(\mathrm{~d}-1$ vs. $\mathrm{d}+7)$ \\
\hline $\begin{array}{c}\text { CD8+ } \\
\text { Lymphocytes }\end{array}$ & $276[51 ; 617]$ & $345[39 ; 868]$ & $\underline{0.023}$ & $604[62 ; 869]$ & $\underline{0.011}$ & $267[44 ; 1078]$ & $394[91 ; 1289]$ & $\underline{0.007}$ & $344[90 ; 816]$ & 0.575 \\
\hline CD4+CD8+ & $1[0 ; 0]$ & $2[0 ; 11]$ & 0.285 & $3[0 ; 15]$ & 0.327 & $2[0 ; 12]$ & $3[0 ; 9]$ & 0.959 & $3[0 ; 11]$ & 0.674 \\
\hline memory & $136[10 ; 439]$ & $204[21 ; 625]$ & 0.11 & $216[31 ; 620]$ & $\underline{0.038}$ & $155[20 ; 670]$ & $168[68 ; 803]$ & $\underline{0.019}$ & $176[58 ; 523]$ & 0.374 \\
\hline $\begin{array}{c}\text { central } \\
\text { memory }\end{array}$ & $38[0 ; 143]$ & $49[0 ; 130]$ & 0.075 & $56.5[0 ; 114]$ & 0.314 & $57[2 ; 193]$ & $62[2 ; 164]$ & 0.173 & $65[1 ; 126]$ & 0.26 \\
\hline naive & $17[1 ; 67]$ & $18[1 ; 90]$ & $\underline{0.041}$ & $32[3 ; 119]$ & $\underline{0.028}$ & $20[7 ; 225]$ & $31[10 ; 218]$ & 0.099 & $26[8 ; 124]$ & 0.515 \\
\hline $\begin{array}{l}\text { effector } \\
\text { memory }\end{array}$ & $147[29 ; 396]$ & $158[23 ; 581]$ & 0.05 & $264[29 ; 615]$ & $\underline{0.028}$ & $120[22 ; 524]$ & $130[44 ; 704]$ & 0.075 & $127[42 ; 590]$ & 0.515 \\
\hline EMRA & 43 [6;281] & $46[9 ; 369]$ & $\underline{0.041}$ & $117[4 ; 376]$ & $\underline{0.011}$ & $87[13 ; 602]$ & $89[8 ; 757]$ & $\underline{0.015}$ & 49 [6;131] & 0.953 \\
\hline early & $97[20 ; 273]$ & $100[15 ; 236]$ & 0.123 & $82[22 ; 668]$ & $\underline{0.038}$ & $111[25 ; 390]$ & $150[54 ; 398]$ & 0.05 & $113[52 ; 255]$ & 0.878 \\
\hline intermediate & $40[16 ; 79]$ & $52[11 ; 118]$ & $\underline{0.015}$ & $46[11 ; 130]$ & $\underline{0.015}$ & $34[12 ; 147]$ & $51[19 ; 205]$ & $\underline{0.039}$ & $49[17 ; 95]$ & 0.386 \\
\hline late & $53[10 ; 441]$ & $43[12 ; 633]$ & 0.05 & $317[8 ; 644]$ & $\underline{0.021}$ & $60[6 ; 703]$ & $93[13 ; 910]$ & $\underline{0.039}$ & $71[14 ; 640]$ & 0.285 \\
\hline exhausted & $134[32 ; 459]$ & $210[26 ; 675]$ & $\underline{0.034}$ & $266[41 ; 558]$ & $\underline{0.021}$ & $170[26 ; 465]$ & $232[63 ; 437]$ & $\underline{0.013}$ & $240[65 ; 383]$ & 0.878 \\
\hline $\begin{array}{l}\text { terminal } \\
\text { effector }\end{array}$ & $31[1 ; 141]$ & $29[2 ; 341]$ & 0.075 & $182[1 ; 229]$ & $\underline{0.011}$ & $30[1 ; 549]$ & $38[1 ; 678]$ & 0.131 & $34[1 ; 389]$ & 0.139 \\
\hline HLA-DR+ & $168[11 ; 549]$ & $165[8 ; 740]$ & $\underline{0.041}$ & $371[12 ; 766]$ & $\underline{0.009}$ & $205[9 ; 701]$ & $225[16 ; 813]$ & $\underline{0.007}$ & $220[7 ; 602]$ & 0.799 \\
\hline CD69+ & $15[3 ; 66]$ & $12[6 ; 69]$ & 0.534 & $25[4 ; 192]$ & 0.26 & $16[4 ; 208]$ & $19[9 ; 203]$ & 0.182 & $15[4 ; 73]$ & 0.721 \\
\hline regulatory & $0[0 ; 7]$ & $0[0 ; 7]$ & 0.678 & $0[0 ; 10]$ & 0.463 & $0[0 ; 1]$ & $0[0 ; 4]$ & 0.075 & $0[0 ; 4]$ & 0.5 \\
\hline CD25+ & $0[0 ; 1]$ & $0[0 ; 2]$ & 0.878 & $0[0 ; 1]$ & 0.249 & $0[0 ; 1]$ & $0[0 ; 1]$ & 0.721 & $0[0 ; 0]$ & 0.499 \\
\hline CD56+ $T$ cells & $7[1 ; 59]$ & $9[0 ; 41]$ & $\underline{0.041}$ & $7[2 ; 60]$ & $\underline{0.021}$ & $6[1 ; 52]$ & $9[2 ; 48]$ & $\underline{0.017}$ & $7[1 ; 35]$ & 0.767 \\
\hline
\end{tabular}

Numbers are median values $/ \mu \mathrm{L}$ and minimum and maximum values in square brackets. EMRA: effector memory RA+.

Additionally, at day +7 , memory $(p=0.038)$, effector memory $(p=0.028)$, early $(p=0.038)$, late $(p=0.021)$, and terminal effector $(p=0.011)$ CD8+ subsets also showed higher values compared to day -1 . Hence, the increase in the total number of CD8+lymphocytes between day +1 and day +7 occurred predominantly in the subsets involved in the activation of the cellular immune system (effector memory, EMRA, late, exhausted, terminal effector, and activated cells), whereas numbers of early CD8+ lymphocytes decreased. No differences were observed between fresh and cryopreserved DLI.

Applying the highest dose of $5 \times 10^{6} \mathrm{CD} 3+$ cells $/ \mathrm{kg}$ also led to a significant increase at day +1 after DLI in CD8+ lymphocytes ( $p=0.007$, Figure 1$)$ and various subsets: Memory $(p=0.019)$, EMRA $(p=0.015)$, intermediate $(p=0.039)$, late $(p=0.039)$, exhausted $(p=0.013)$, and activated memory (HLA-DR+, $p=0.007$ ) (Table 3 ).

Regarding CD56+ T cells, we observed a significant increase at day $+1(p=0.041)$ and day $+7(p=0.021)$, compared to the measurement before the administration of $1 \times 10^{6} \mathrm{CD} 3+$ cells $/ \mathrm{kg}$. Further, applying a higher dosage of $5 \times 10^{6} \mathrm{CD} 3+$ cells $/ \mathrm{kg}$ led to a significant increase at day +1 post DLI $(p=0.017)$ (Table 3$)$.

\subsubsection{NK Cells}

Among NK cells, we analyzed CD56+ CD16+, CD56 bright CD16 dim, and CD56 $\operatorname{dim}$ CD16 bright lymphocytes. A significant increase could be observed for the overall NK cells population as well as for the subset of CD56+CD16+ cells at day +7 after the application of the highest DLI dosage of $5 \times 10^{6} \mathrm{CD} 3+$ cells $/ \mathrm{kg}(p=0.037$ and $p=0.017$, 
respectively; Table 4). No significant changes were observed after DLI in the lowest dosage of $2 \times 10^{5} \mathrm{CD} 3+$ cells $/ \mathrm{kg}$ (Supplemental Table S7).

Table 4. NK cells.

\begin{tabular}{|c|c|c|c|c|c|c|c|c|c|c|}
\hline \multirow[t]{2}{*}{ Dose } & \multicolumn{5}{|c|}{$1 \times 10^{6}$} & \multicolumn{5}{|c|}{$5 \times 10^{6}$} \\
\hline & $d-1$ & $d+1$ & $p(\mathrm{~d}-1$ vs. $\mathrm{d}+1)$ & $d+7$ & $p(\mathrm{~d}-1$ vs. $\mathrm{d}+7)$ & $d-1$ & $d+1$ & $p(\mathrm{~d}-1$ vs. $\mathrm{d}+1)$ & $d+7$ & $p(\mathrm{~d}-1$ vs. $\mathrm{d}+7)$ \\
\hline NK cells & $158[88 ; 441]$ & $196[125 ; 369]$ & 1.0 & $231[66 ; 322]$ & 0.374 & $162[93 ; 401]$ & $208[93 ; 387]$ & 0.917 & $189[127 ; 438]$ & 0.037 \\
\hline CD56+CD16+ & $97[44 ; 289]$ & $106[62 ; 252]$ & 0.695 & $112[43 ; 251]$ & 0.26 & $104[49 ; 289]$ & $104[66 ; 280]$ & 0.463 & $130[64 ; 305]$ & $\underline{0.017}$ \\
\hline $\begin{array}{l}\text { CD56bright } \\
\text { CD16dim }\end{array}$ & $36[18 ; 229]$ & $42[17 ; 203]$ & 0.328 & $36[13 ; 223]$ & 0.859 & $36[13 ; 211]$ & $37[16 ; 76]$ & 0.552 & $29[15 ; 101]$ & 0.285 \\
\hline $\begin{array}{l}\text { CD56dim } \\
\text { CD16bright }\end{array}$ & $23[10 ; 158]$ & $31[8 ; 86]$ & 0.859 & $37[6 ; 78]$ & 0.374 & $27[7 ; 120]$ & $20[4 ; 101]$ & 0.917 & $23[12 ; 164]$ & 0.445 \\
\hline
\end{tabular}

Numbers are median values $/ \mu \mathrm{L}$ and minimum and maximum values in square brackets. NK: Natural Killer.

\subsubsection{B Lymphocytes}

As internal negative control, we measured absolute B lymphocytes and their subsets (naïve, memory, class-switch, and transitional). No significant changes were seen after DLI (Figure 1 and Supplemental Table S8).

\subsubsection{Subgroup Analysis on Recipients of Preemptive DLI}

A subgroup analysis was performed among patients receiving preemptive DLI, since increasing chimerism and achievement of $\mathrm{CRm}$ can be regarded as clinical evidence for an effective alloreactive, respectively, GvL reaction. All eight patients responded. Similarly to the entire cohort, a significant increase of various CD8+ subsets and some CD4+ subsets was observed at day +1 and day +7 after the administration of $1 \times 10^{6} \mathrm{CD} 3+$ cells $/ \mathrm{kg}$ (see Supplemental Table S9 for detailed results).

\subsubsection{Subgroup Analysis on Patients Developing GvHD}

Further, we analyzed all patients who developed acute or chronic GvHD after DLI of $\geq 5 \times 10^{6} \mathrm{CD} 3+$ cells $/ \mathrm{kg}(n=5)$. After DLI of $2 \times 10^{5}$ or $1 \times 10^{6} \mathrm{CD} 3+$ cells $/ \mathrm{kg}$, no GvHD occurred. We observed a significant increase in activated CD8+ lymphocytes at day +1 after DLI of $5 \times 10^{6}$ CD3 + cells $/ \mathrm{kg}$. CD8+CD69+ cells increased from $15 / \mu \mathrm{L}$ ( $5.6 \%$ of CD8+ cells) to $35 / \mu \mathrm{L}(13 \%$ of CD8+ cells) $(p=0.04)$. In contrast, this was not observed in patients who did not develop GvHD (4.6\% of all CD8+ cells at day -1 and $3.7 \%$ at day +1$)$.

\section{Discussion}

Applying donor lymphocyte infusion (DLI) to a patient with an established chimerism after alloSCT is a frequently used method to enhance the GvL effect $[1,2,4,6]$. Whereas several studies explored $\mathrm{T}$ cell recovery after alloSCT [23-25], only one analyzed delayed changes in lymphocyte subsets and T cell response after DLI [26]. No data are available on lymphocyte alterations during the early phase after DLI. To address this, we measured the changes of various peripheral blood B and T cell subsets as well as CD56+ T and NK cells at day +1 and day +7 after DLI, applied in increasing doses to an unselected cohort of consecutively treated patients.

In a first observation, we found lower overall numbers of lymphocytes and their subsets among our patients before DLI as compared to healthy controls, indicating an incomplete immune reconstitution after alloSCT. However, even application of up to three infusions in escalating cell doses, i.e., after an interval of 8-12 weeks from first DLI, did not lead to an overall increase of total lymphocytes, nor CD3+ T cells. Hence, at least based on overall peripheral lymphocyte counts as a surrogate marker, repeated DLI were unable to accelerate cellular immune reconstitution.

In contrast, significant early changes in various $\mathrm{T}$ lymphocyte subsets were observed after DLI in a dose-dependent fashion. Despite of their exploratory nature, these are the first data describing, in detail, early changes of peripheral lymphocytes following unmodified 
DLI, which, although being transient, might be a hint for reactions occurring in the tissue and lymphatic organs. In detail, we found significant increases in the overall CD8+ counts and various subsets at day +1 and day +7 after the application of $1 \times 10^{6} \mathrm{CD} 3+$ cells $/ \mathrm{kg}$.

Changes at day +1 might be a consequence of the addition of CD8+ cells to the pool of circulating lymphocytes by the infusion itself. However, the remarkable increase in the total number of CD8+ lymphocytes between day +1 and day +7 was particularly observed in the activated cellular subsets (effector memory, EMRA, late, exhausted, terminal effector, and activated cells), whereas early CD8+ lymphocytes decreased. Possible explanations might be an effective stimulation and proliferation of the transfused lymphocytes themselves or an overall stimulating effect of DLI on the effector cell system within the recipient. In contrast, an increase of CD4+ cells was only observed at day +1 after the administration of the highest analyzed dose of $5 \times 10^{6} \mathrm{CD} 3+$ cells $/ \mathrm{kg}$.

Alterations of peripheral blood lymphocytes might occur for various reasons, including infections, other acute inflammatory reactions, and GvHD. Among our patients, infectious stimuli can be excluded to the greatest extent, since the absence of infections was a clinical prerequisite for the application of DLI, as was ongoing GvHD. Beyond this, we did not observe clinical signs of infections early after DLI. In contrast, the changes observed in our study might reflect an unspecific, polyclonal alloreaction, as freshly collected donor lymphocytes have not undergone tolerance induction and might, therefore, be activated by contact with allogeneic tissue.

This cannot be ruled out by our data since we did not perform tests, like spectra typing or T-cell receptor sequencing, to distinguish oligoclonal expansion of specific $\mathrm{T}$ cells from polyclonal activation. Nevertheless, it can also be hypothesized that early numeric and functional changes among lymphocyte subpopulations are associated with specific alloreactivity against the malignant disease. Both CD4+ and CD8+ lymphocytes are discussed as effector cells for a GvL reaction [27-29]. In our cohort, both memory and activated as well as exhausted CD8 $+\mathrm{T}$ cell subsets showed a significant increase at day +1 and day +7 after application of $1 \times 10^{6} \mathrm{CD} 3+$ cells $/ \mathrm{kg}$ and at day +1 after $5 \times 10^{6} \mathrm{CD} 3+$ cells $/ \mathrm{kg}$, respectively (Table 3 ).

Likewise, in a subgroup analysis of patients achieving a response and long-term disease control upon preemptive DLI $(n=8)$, a significant increase in these CD8+ T cell subsets was observed after the application of $1 \times 10^{6} \mathrm{CD} 3+$ cells $/ \mathrm{kg}$ (Supplemental Table S9). Due to the $100 \%$ response rate among these recipients of preemptive DLI, we could not compare changes among responding versus non-responding patients.

Low patient numbers precluded the determination of predictive markers for response by multivariate analysis. Nevertheless, preemptive DLI might be an appropriate scenario to study GvL reactions, since achieving CRm after molecular relapse or MRD represents a clinically relevant and measurable example for a GvL reaction. Similarly, conversion from $\mathrm{MC}$ to full chimerism carries characteristics of an anti-tumor immune response since $\mathrm{MC}$ has been frequently associated with incipient relapse [30]. Concurrently, conversion of chimerism could also be a consequence of an unspecific alloreaction.

Assuming a role of early predominant CD8+ increase for a GvL effect, this observation would support earlier studies showing specific antileukemic reactivity of CD8+ cells both directed against minor histocompatibility and tumor-associated antigens [12,31,32]. The role of CD8+ cells is further supported by clinical studies from the literature that have used CD4+ selected instead of unmodified donor lymphocytes for DLI to enhance the GvL effect or to diminish the occurrence of GvHD but failed to show superiority of this approach $[27,33]$.

In the only study analyzing T cell subpopulations after DLI thus far, Hofmann et al., studied the frequency and diversity of the leukemia-associated antigen $\mathrm{T}$ cell response at a median of eight months after DLI. At this delayed time point, they did not find any differences in the CD8+ T cell subsets in the peripheral blood comparing clinical responders and non-responders, but detected a significant decrease of regulatory CD4+ cells in patients responding to DLI [26]. In our study, we found significant changes in the 
total CD4+ lymphocytes, particularly in the memory and central memory subsets on day + 1 after the application of the highest dose of $5 \times 10^{6} \mathrm{CD} 3+$ cells $/ \mathrm{kg}$. Possibly these memory cells migrate into the in lymphoid tissue and can, therefore, no longer be measured at day +7 .

NK cells play a role in controlling malignancies [34,35] and viral infections, like CMV [36], but also in triggering alloreactivity [37]. The significant increase of NK cells day +7 post DLI with $5 \times 10^{6} \mathrm{CD} 3+$ cells $/ \mathrm{kg}(p=0.037)$ adds to the theory that NK cells could contribute to alloreactivity [12]. A close interaction between the activation of cytotoxic T cells and NK cells has been described [38].

Five of our patients developed acute or chronic GvHD after DLI of $5 \times 10^{6} \mathrm{CD} 3+$ cells $/ \mathrm{kg}$ or higher doses. In these patients, activated CD8+CD69+ T lymphocytes increased significantly at day +1 . This was not the case among patients without GvHD. Hence, it might be speculated that activated CD8+CD69+ T cells could be further investigated as an early prognostic marker for the risk of GvHD [39]. Low patient numbers precluded further analysis or comparison among patients with and without GvHD. Considering the composition of the transfused cells during DLI, a higher number of CD27+ B-cells, but no $\mathrm{T}$ cell subsets, were associated with GvHD [40]. Beyond this, other factors, such as the number of transfused lymphocytes, have been associated with DLI-induced GvHD [41].

In summary, within the limitations of relatively low patient numbers and some clinical heterogenicity, our study describes a significant increase in various lymphocyte subsets early after unmodified DLI. Subsets of activated CD8+ T cells represented the most clearly changing cellular population. As we could not distinguish between unspecific polyclonal stimulation and the expansion of specific oligoclonal subsets in the present study, dedicated investigations, such as spectra typing or T-cell receptor sequencing, are warranted to further characterize the expansion and function of transfused donor lymphocytes.

Supplementary Materials: The following are available online at https: / www.mdpi.com/article / 10.3390/hemato2040046/s1, Figure S1: Gating strategy, Figure S2A: Overall survival in the total cohort, Figure S2B: Overall survival in patients treated preemptively or prophylactically with DLI, Table S1: Antibodies, Table S2: Identification of lymphocyte subsets, Table S3: Individual patient information, Table S4: Comparison to healthy control group, Table S5: CD4+ lymphocytes after DLI of $2 \times 10^{5} \mathrm{CD} 3+$ cells $/ \mathrm{kg}$, Table S6: CD8+ lymphocytes and CD56+ T cells after DLI of $2 \times 10^{5} \mathrm{CD} 3+$ cells $/ \mathrm{kg}$, Table S7: NK cells after DLI of $2 \times 10^{5} \mathrm{CD} 3+$ cells $/ \mathrm{kg}$, Table S8: B lymphocytes, Table S9: Subgroup analysis preemptive DLI.

Author Contributions: A.-K.S. designed the study, analyzed and interpreted data, and drafted the manuscript, J.W. drafted the manuscript, D.K. contributed to data acquisition, T.L. prepared samples and conducted flow cytometry, S.G. was responsible for the technical equipment and standardized execution of flow cytometry measurements, R.C. created Figure 1, M.T. drafted the manuscript, C.S. interpreted data and drafted the manuscript, A.R. designed the study, created Supplemental Figure S2A,B, analyzed and interpreted data, and drafted the manuscript. All authors have read and agreed to the published version of the manuscript.

Funding: This research received no external funding.

Institutional Review Board Statement: The study was conducted according to the guidelines of the Declaration of Helsinki and approved by the Institutional Ethical Review Board of the Augsburg University Hospital (date of approval: 10 October 2016).

Informed Consent Statement: Informed consent was obtained from all subjects involved in the study. Acknowledgments: We appreciate the help of Susanne Lison and the entire laboratory staff for the technical support.

Conflicts of Interest: The authors declare no conflict of interest.

\section{References}

1. Kolb, H.J.; Mittermuller, J.; Clemm, C.; Holler, E.; Ledderose, G.; Brehm, G.; Heim, M.; Wilmanns, W. Donor leukocyte transfusions for treatment of recurrent chronic myelogenous leukemia in marrow transplant patients. Blood 1990, 76, 2462-2465. [CrossRef] 
2. Deol, A.; Lum, L.G. Role of donor lymphocyte infusions in relapsed hematological malignancies after stem cell transplantation revisited. Cancer Treat. Rev. 2010, 36, 528-538. [CrossRef] [PubMed]

3. Schmid, C.; Labopin, M.; Nagler, A.; Bornhäuser, M.; Finke, J.; Fassas, A.; Volin, L.; Gürman, G.; Maertens, J.; Bordigoni, P.; et al. Donor Lymphocyte Infusion in the Treatment of First Hematological Relapse After Allogeneic Stem-Cell Transplantation in Adults with Acute Myeloid Leukemia: A Retrospective Risk Factors Analysis and Comparison with Other Strategies by the EBMT Acute Leukemia Working Party. J. Clin. Oncol. 2007, 25, 4938-4945. [CrossRef] [PubMed]

4. Chang, Y.-J.; Huang, X.-J. Donor lymphocyte infusions for relapse after allogeneic transplantation. When, if and for whom? Blood Rev. 2013, 27, 55-62. [CrossRef] [PubMed]

5. Döhner, H.; Estey, E.; Grimwade, D.; Amadori, S.; Appelbaum, F.R.; Büchner, T.; Dombret, H.; Ebert, B.L.; Fenaux, P.; Larson, R.A.; et al. Diagnosis and management of AML in adults: 2017 ELN recommendations from an international expert panel. Blood 2017, 129, 424-447. [CrossRef] [PubMed]

6. Schmid, C.; Labopin, M.; Schaap, N.; Veelken, H.; Schleuning, M.; Stadler, M.; Finke, J.; Hurst, E.; Baron, F.; Ringden, O.; et al. Prophylactic donor lymphocyte infusion after allogeneic stem cell transplantation in acute leukaemia-A matched pair analysis by the Acute Leukaemia Working Party of EBMT. Br. J. Haematol. 2019, 184, 782-787. [CrossRef] [PubMed]

7. Huang, X.-J.; Wang, Y.; Liu, D.-H.; Xu, L.-P.; Chen, H.; Chen, Y.-H.; Han, W.; Shi, H.-X.; Liu, K.-Y. Modified Donor Lymphocyte Infusion (DLI) for the Prophylaxis of Leukemia Relapse after Hematopoietic Stem Cell Transplantation in Patients with Advanced Leukemia-Feasibility and Safety Study. J. Clin. Immunol. 2008, 28, 390-397. [CrossRef]

8. Dominietto, A.; Pozzi, S.; Miglino, M.; Albarracin, F.; Piaggio, G.; Bertolotti, F.; Grasso, R.; Zupo, S.; Raiola, A.M.; Gobbi, M.; et al. Donor lymphocyte infusions for the treatment of minimal residual disease in acute leukemia. Blood 2007, 109, 5063-5064. [CrossRef]

9. Rettinger, E.; Willasch, A.M.; Kreyenberg, H.; Borkhardt, A.; Holter, W.; Kremens, B.; Strahm, B.; Woessmann, W.; Mauz-Koerholz, C.; Gruhn, B.; et al. Preemptive immunotherapy in childhood acute myeloid leukemia for patients showing evidence of mixed chimerism after allogeneic stem cell transplantation. Blood 2011, 118, 5681-5688. [CrossRef]

10. Tsirigotis, P.; Byrne, M.; Schmid, C.; Baron, F.; Ciceri, F.; Esteve, J.; Gorin, N.C.; Giebel, S.; Mohty, M.; Savani, B.N.; et al. Relapse of AML after hematopoietic stem cell transplantation: Methods of monitoring and preventive strategies. A review from the ALWP of the EBMT. Bone Marrow Transplant. 2016, 51, 1431-1438. [CrossRef]

11. Zeiser, R.; Beelen, D.W.; Bethge, W.; Bornhäuser, M.; Bug, G.; Burchert, A.; Christopeit, M.; Duyster, J.; Finke, J.; Gerbitz, A.; et al. Biology-Driven Approaches to Prevent and Treat Relapse of Myeloid Neoplasia after Allogeneic Hematopoietic Stem Cell Transplantation. Biol. Blood Marrow Transplant. 2019, 25, e128-e140. [CrossRef] [PubMed]

12. Dickinson, A.M.; Norden, J.; Li, S.; Hromadnikova, I.; Schmid, C.; Schmetzer, H.; Jochem-Kolb, H. Graft-versus-Leukemia Effect Following Hematopoietic Stem Cell Transplantation for Leukemia. Front. Immunol. 2017, 8, 496. [CrossRef] [PubMed]

13. Zheng, H.; Matte-Martone, C.; Jain, D.; McNiff, J.; Shlomchik, W.D. Central Memory CD8+T Cells Induce Graft-versus-Host Disease and Mediate Graft-versus-Leukemia. J. Immunol. 2009, 182, 5938-5948. [CrossRef] [PubMed]

14. Goulmy, E. Human minor histocompatibility antigens: New concepts for marrow transplantation and adoptive immunotherapy. Immunol. Rev. 1997, 157, 125-140. [CrossRef] [PubMed]

15. Falkenburg, J.H.F.; van de Corput, L.; Marijt, E.W.A.; Willemze, R. Minor histocompatibility antigens in human stem cell transplantation. Exp. Hematol. 2003, 31, 743-751. [CrossRef]

16. Miller, J.S.; Warren, E.H.; van den Brink, M.R.M.; Ritz, J.; Shlomchik, W.D.; Murphy, W.J.; Barrett, A.J.; Kolb, H.J.; Giralt, S.; Bishop, M.R.; et al. NCI First International Workshop on The Biology, Prevention, and Treatment of Relapse after Allogeneic Hematopoietic Stem Cell Transplantation: Report from the Committee on the Biology Underlying Recurrence of Malignant Disease following Allogeneic HSCT: Graft-versus-Tumor/Leukemia Reaction. Biol. Blood Marrow Transplant. 2010, 16, 565-586. [CrossRef]

17. Schmid, C.; Schleuning, M.; Ledderose, G.; Tischer, J.; Kolb, H.-J. Sequential Regimen of Chemotherapy, Reduced-Intensity Conditioning for Allogeneic Stem-Cell Transplantation, and Prophylactic Donor Lymphocyte Transfusion in High-Risk Acute Myeloid Leukemia and Myelodysplastic Syndrome. J. Clin. Oncol. 2005, 23, 5675-5687. [CrossRef]

18. Jedlickova, Z.; Schmid, C.; Koenecke, C.; Hertenstein, B.; Baurmann, H.; Schwerdtfeger, R.; Tischer, J.; Kolb, H.-J.; Schleuning, M. Long-term results of adjuvant donor lymphocyte transfusion in AML after allogeneic stem cell transplantation. Bone Marrow Transplant. 2016, 51, 663-667. [CrossRef]

19. Streitz, M.; Miloud, T.; Kapinsky, M.; Reed, M.R.; Magari, R.; Geissler, E.K.; Hutchinson, J.A.; Vogt, K.; Schlickeiser, S.; Kverneland, A.H.; et al. Standardization of whole blood immune phenotype monitoring for clinical trials: Panels and methods from the ONE study. Transplant. Res. 2013, 2, 17. [CrossRef]

20. Waidhauser, J.; Schuh, A.; Trepel, M.; Schmälter, A.-K.; Rank, A. Chemotherapy markedly reduces B cells but not T cells and NK cells in patients with cancer. Cancer Immunol. Immunother. 2020, 69, 147-157. [CrossRef]

21. Rank, A.; Löhr, P.; Hoffmann, R.; Ebigbo, A.; Grützner, S.; Schmid, C.; Claus, R. Sustained cellular immunity in adults recovered from mild COVID-19. Cytom. Part A 2021, 99, 429-434. [CrossRef]

22. Schmaelter, A.-K.; Labopin, M.; Socié, G.; Itälä-Remes, M.; Blaise, D.; Yakoub-Agha, I.; Forcade, E.; Cornelissen, J.; Ganser, A.; Beelen, D.; et al. Inferior outcome of allogeneic stem cell transplantation for secondary acute myeloid leukemia in first complete remission as compared to de novo acute myeloid leukemia. Blood Cancer J. 2020, 10, 26. [CrossRef] [PubMed] 
23. Van Den Brink, M.R.M.; Velardi, E.; Perales, M.-A. Immune reconstitution following stem cell transplantation. Hematology 2015, 2015, 215-219. [CrossRef] [PubMed]

24. Naik, S.; Vasileiou, S.; Aguayo-Hiraldo, P.; Mukhi, S.; Sasa, G.; Martinez, C.; Krance, R.A.; Gottschalk, S.; Leen, A. Toward Functional Immune Monitoring in Allogeneic Stem Cell Transplant Recipients. Biol. Blood Marrow Transplant. 2020, 26, 911-919. [CrossRef] [PubMed]

25. Ogonek, J.; Juric, M.K.; Ghimire, S.; Varanasi, P.R.; Holler, E.; Greinix, H.; Weissinger, E. Immune Reconstitution after Allogeneic Hematopoietic Stem Cell Transplantation. Front. Immunol. 2016, 7, 507. [CrossRef]

26. Hofmann, S.; Schmitt, M.; Götz, M.; Döhner, H.; Wiesneth, M.; Bunjes, D.; Greiner, J. Donor lymphocyte infusion leads to diversity of specific T cell responses and reduces regulatory $\mathrm{T}$ cell frequency in clinical responders. Int. J. Cancer 2019, 144, 1135-1146. [CrossRef] [PubMed]

27. Van Balen, P.; Van Bergen, C.A.M.; Van Luxemburg-Heijs, S.A.P.; De Klerk, W.; Van Egmond, E.H.M.; Veld, S.A.J.; Halkes, C.J.M.; Zwaginga, J.-J.; Griffioen, M.; Jedema, I.; et al. CD4 Donor Lymphocyte Infusion Can Cause Conversion of Chimerism Without GVHD by Inducing Immune Responses Targeting Minor Histocompatibility Antigens in HLA Class II. Front. Immunol. 2018, 9, 3016. [CrossRef]

28. Van Bergen, C.A.M.; Van Luxemburg-Heijs, S.A.P.; De Wreede, L.C.; Eefting, M.; Von Dem Borne, P.A.; Van Balen, P.; Heemskerk, M.H.M.; Mulder, A.; Claas, F.H.J.; Navarrete, M.A.; et al. Selective graft-versus-leukemia depends on magnitude and diversity of the alloreactive T cell response. J. Clin. Investig. 2017, 127, 517-529. [CrossRef]

29. Bleakley, M.; Riddell, S.R. Molecules and mechanisms of the graft-versus-leukaemia effect. Nat. Rev. Cancer 2004, 4, 371-380. [CrossRef]

30. Bouvier, A.; Riou, J.; Thepot, S.; Del Galy, A.S.; François, S.; Schmidt, A.; Orvain, C.; Estienne, M.-H.; Villate, A.; Paz, D.L.; et al. Quantitative chimerism in CD3-negative mononuclear cells predicts prognosis in acute myeloid leukemia patients after hematopoietic stem cell transplantation. Leukemia 2020, 34, 1342-1353. [CrossRef]

31. Zorn, E.; Wang, K.S.; Hochberg, E.P.; Canning, C.; Alyea, E.P.; Soiffer, R.J.; Ritz, J. Infusion of CD4+ donor lymphocytes induces the expansion of CD8+ donor T cells with cytolytic activity directed against recipient hematopoietic cells. Clin. Cancer Res. 2002, 8, 2052-2060. [PubMed]

32. Greiner, J.; Ono, Y.; Hofmann, S.; Schmitt, A.; Mehring, E.; Götz, M.; Guillaume, P.; Döhner, K.; Mytilineos, J.; Döhner, H.; et al. Mutated regions of nucleophosmin 1 elicit both CD4(+) and CD8(+) T-cell responses in patients with acute myeloid leukemia. Blood 2012, 120, 1282-1289. [CrossRef] [PubMed]

33. Soiffer, R.J.; Alyea, E.P.; Hochberg, E.; Wu, C.; Canning, C.; Parikh, B.; Zahrieh, D.; Webb, I.; Antin, J.; Ritz, J. Randomized trial of CD8+ T-cell depletion in the prevention of graft-versus-host disease associated with donor lymphocyte infusion. Biol. Blood Marrow Transplant. 2002, 8, 625-632. [CrossRef]

34. Waldhauer, I.; Steinle, A. NK cells and cancer immunosurveillance. Oncogene 2008, 27, 5932-5943. [CrossRef] [PubMed]

35. Shimasaki, N.; Jain, A.; Campana, D. NK cells for cancer immunotherapy. Nat. Rev. Drug Discov. 2020, 19, 200-218. [CrossRef]

36. Orr, M.T.; Lanier, L.L. Natural Killer Cell Education and Tolerance. Cell 2010, 142, 847-856. [CrossRef]

37. Ruggeri, L.; Mancusi, A.; Burchielli, E.; Capanni, M.; Carotti, A.; Aloisi, T.; Aversa, F.; Martelli, M.F.; Velardi, A. NK cell alloreactivity and allogeneic hematopoietic stem cell transplantation. Blood Cells Mol. Dis. 2008, 40, 84-90. [CrossRef]

38. Uzhachenko, R.V.; Shanker, A. CD8+ T Lymphocyte and NK Cell Network: Circuitry in the Cytotoxic Domain of Immunity. Front. Immunol. 2019, 10, 1906. [CrossRef]

39. Paz Morante, M.; Briones, J.; Canto, E.; Sabzevari, H.; Martino, R.; Sierra, J.; Rodriguez-Sanchez, J.L.; Vidal, S. Activationassociated phenotype of CD3+ T cells in acute graft-versus-host disease. Clin. Exp. Immunol. 2006, 145, 36-43. [CrossRef]

40. Ortí, G.; Palacio-Garcia, C.; García-Cadenas, I.; Sánchez-Ortega, I.; Jimenez, M.J.; Azqueta, C.; Villacampa, G.; Ferrà, C.; Parody, R.; Martino, R.; et al. Analysis of Cell Subsets in Donor Lymphocyte Infusions from HLA Identical Sibling Donors after Allogeneic Hematopoietic Cell Transplant. Transplant. Cell. Ther. 2020, 27, 53.e1-53.e8. [CrossRef] [PubMed]

41. Guglielmi, C.; Arcese, W.; Dazzi, F.; Brand, R.; Bunjes, D.; Verdonck, L.F.; Schattenberg, A.; Kolb, H.-J.; Ljungman, P.; Devergie, A.; et al. Donor lymphocyte infusion for relapsed chronic myelogenous leukemia: Prognostic relevance of the initial cell dose. Blood 2002, 100, 397-405. [CrossRef] [PubMed] 